DOI:

http://dx.doi.org/10.15448/1983-4012.2016.1.22800

\title{
OPERATIONAL VARIABLES AND META-THEOREMS
}

\author{
Variáveis Operacionais e Meta-teoremas
}

Guilherme Kubiszeski*

\begin{abstract}
This paper deals with the notion of an operational variable in metalogical contexts. After a clarification of the notion itself through an example concerning identity of reference, a few meta-theorems regarding the property of theoremicity are presented. These meta-theorems articulate, with a high degree of generality, the concepts of a set of formulae, deducibility and operation over sets. Operational variables are shown to be useful for stating some interesting results in classical logic. Such results guarantee the intelligibility of the notion of an operational variable, as no extra-logical concepts are employed in the proofs, but only well-known notions and rules.
\end{abstract}

Keywords: Operational variables. Metalogic. Theoremicity.
Resumo: Este artigo aborda a noção de variável operacional em contextos meta-lógicos. Após uma clarificação desta noção por meio de um exemplo relativo à identidade de referência, alguns meta-teoremas concernentes à propriedade de teoremicidade são apresentados. Estes metateoremas articulam, com um alto grau de generalidade, os conceitos de conjunto de formulas, dedutibilidade e operação sobre conjuntos. Mostra-se que variáveis operacionais são úteis na enunciação de alguns resultados interessantes na lógica clássica. Tais resultados garantem a inteligibilidade da noção de variável operacional, na medida em que nenhum conceito extra-lógico é empregado nas provas, mas apenas regras e noções conhecidas.

Palavras-chave: Variáveis operacionais. Metalógica. Teoremicidade.

\footnotetext{
* Mestrando em Filosofia pela UNB. E-mail: guilhermefk4@gmail.com
}

\begin{tabular}{|c|c|l|l|l|l|}
\hline intuitio & ISSN & Porto Alegre & Vol.9- $\mathrm{N}^{\mathrm{o}} .1$ & $\begin{array}{l}\text { Julho } \\
2016\end{array}$ & p.28-34 \\
\hline
\end{tabular}




\section{Introduction}

From a historical point of view, it is safe to say that Aristotle is responsible for introducing variables into $\operatorname{logic}^{1}$. It is also known that the Stoics used variables to state the rules of their system of propositional logic, thus introducing the concept of a propositional variable ${ }^{2}$. In first-order logic, a remarkable feature of these letters is their lending themselves to talk of objects of any sort whatsoever ${ }^{3}$. In this sense, a variable might range over a domain containing numbers, sets, physical objects, events and so forth.

The distinction between object language and metalanguage leads us to tell apart variables from metavaribles. The latter are template-texts that have as substituents syntactic items from the object language alphabet ${ }^{4}$. While variables are genuine elements of such an alphabet, metavariables are mere place-holders. Nevertheless, one can neither present a logical system nor state its meta-results without employing metavariables. Therefore, metalogical symbols that stand for terms, predicates and sentences of some object language are commonplace in axiom schemata, specification of inference rules and metatheorems. A not so common kind of metavariable, however, stands for other elements of the alphabet, i.e., operators. The following example will do for clarifying the working of these metavariables.

Let us assume that a proper criterion for identity, at least for identity between abstract objects such as numbers and sets, can be stated as follows: for every $\mathrm{x}, \mathrm{y}$ and $\mathrm{z}, \mathrm{x}=\mathrm{y}$ if and only if $\mathrm{x} * \mathrm{z}=\mathrm{y} * \mathrm{z}$, whatever the meaning assigned to the symbol '*'. One of the resources employed in this statement, i.e., the symbol '*', which stands for any operator whatsoever, is useful for distinguishing logical identity (identity of denotation) from arithmetical equality. Equations such as ' $\mathrm{x} . \mathrm{y}=\mathrm{y} \cdot \mathrm{x}$ ' and ' $\mathrm{x}+\mathrm{y}=\mathrm{y}+\mathrm{x}$ ', for instance, are not mere statements about what $\mathrm{x}$ and $\mathrm{y}$ denote, but rather say something definite about the symbols '.' and '+' respectively, i.e., that they both commute. Once any of these symbols is replaced with '-' or ' $\div$ ', the resulting statement is clearly false. On the other hand, the level of generality yielded by '*' within the metalinguistic statement presented above allows one to convey the idea of logical identity alone, without saying anything specific about the properties related to some particular arithmetical operator. To put it another way, since something is said about every operator - as the final sentence of the criterion makes clear -, i.e., how they all behave in relation to logical identity, the statement ultimately concerns the latter,

\footnotetext{
${ }^{1}$ LUKASIEWICZ, J. Aristotle's Syllogistic from the Standpoint of Modern Formal Logic. 1.ed. Oxford: Clarendon Press, 1963, pp. 7.

${ }^{2}$ ŁUKASIEWICZ, J. "On the History of the Logic of Propositions". In: MCCALL, S.; AJDUKIEWICZ (Ed.), Polish Logic. 1.ed. Oxford: Clarendon Press, 2005, pp. 66-87.

${ }^{3}$ QUINE, W.V. "Variables Explained Away". Proceedings of the American Philosophical Society, Philadelphia, vol.104, no.3, 343-347, 1960.

${ }^{4}$ CORCORAN, J. "Schemata: the Concept of Schema in the History of Logic". Bulletin of Symbolic Logic, Cambridge, vol.12, no.3, 219-40, 2006.
}

\begin{tabular}{|c|c|c|c|c|c|}
\hline intuitio & $\begin{array}{c}\text { ISSN } \\
1983-4012\end{array}$ & Porto Alegre & Vol.9- $\mathrm{N}^{\circ} .1$ & $\begin{array}{l}\text { Julho } \\
2016\end{array}$ & p.28-34 \\
\hline
\end{tabular}


touching upon the meaning of other operators only secondarily. The same resource, henceforth called "operational variable", can be employed not only to give a criterion for identity, but also to state some substantial results regarding the notion of a theorem in the context of a system $\mathrm{C}$ of classical logic. The aim of this paper is to show how operational variables can occur in meta-theorems that string together, with a high level of generality, the notions of a set of formulae, deducibility and operation over sets.

\section{Meta-theorems}

Let $\mathrm{C}$ be the ordered pair $\langle\mathrm{L}, \vdash>$, where ' $\mathrm{L}$ ' is the formal language of the calculus and ' $\vdash$ ' is the relation of (syntactic) logical consequence in L. Theorems are defined as special cases of deductions, where the set $\Gamma$ of premises from which one derives $\varphi$ (the theorem) is the empty set $(\Gamma=\emptyset)$. It follows that, if $\varphi$ is a theorem, then $\Sigma \vdash \varphi$ for every set $\Sigma$ of well-formed formulae (wffs) of L, since a basic result of classic set theory states that for every set $A, \emptyset \subseteq \mathrm{A}$. This result, along with the assumption regarding the monotonicity of the consequence relation $\vdash$, guarantees that theorems are derivable from all sets of wffs of L.

Operational variables are essentially metalinguistic, since operators make up (wholly or partially, insofar as $\mathrm{C}$ might be, without affecting the results presented below, either a system of sentential logic or of first-order predicate logic ) the part of the syntax of L usually known as the set of logical constants. Therefore, their occurrence in the context of $\mathrm{C}$ cannot be intra-systemic; instead, it is an admissible linguistic resource only within statements concerning the most general features of $\mathrm{C}$. This restriction obviously contrasts with the fact that, all things being equal, sentential and individual variables have both an intra-systemic expression and a metalinguistic one, i.e., not only are they amenable to quantification in metalinguistic contexts, but also appear in the object language, as they make up part of the alphabet of propositional and first-order calculi, respectively. That being said, how can operational variables be used, after all, as a legitimate linguistic resource to convey fundamental features of C? The answer, in accordance with has been previously put forth, is laid down in a few meta-theoretical proofs regarding the notion of a theorem in systems like $\mathrm{C}$ and relies heavily upon long-known results such as the monotonicity of the consequence in such systems and the fact that theorems are deducible from any set of wffs.

To begin with, we assume a metalanguage rich enough to contain the necessary English words plus the following symbols: capital Greek letters (' $\Gamma$ ', ' $\Delta$ ') for sets of wff, small Greek letter (' $\varphi$ ', ' $\psi$ ') for wffs, turnstile (' $\vdash$ ') for the consequence relation syntactically defined, slashed turnstile (' $\forall$ ') to deny that such a relation holds, a few set theory symbols with their usual meanings (' $U$ ', ' $\cap$ ', '-', ' $\subseteq$ ', ' $\emptyset$ ', ' $\in$ ', ' $\notin$ ' ) and $\operatorname{star}\left({ }^{*}\right.$ ') for the operational variable. Then we state the following meta-theorem and next exhibit its proof:

\begin{tabular}{|c|c|l|l|l|l|}
\hline intuitio & $\begin{array}{c}\text { ISSN } \\
1983-4012\end{array}$ & Porto Alegre & Vol.9- $\mathrm{N}^{\mathrm{o}} .1$ & $\begin{array}{l}\text { Julho } \\
2016\end{array}$ & p.28-34 \\
\hline
\end{tabular}


Meta-theorem 1 if $\Gamma \vdash \varphi$ and $\varphi$ is a theorem, then $\Gamma * \Delta \vdash \varphi$ for every set $\Delta$ of wffs and whatever the meaning assigned to *.

Proof we assume that $\Gamma \vdash \varphi$ and that $\varphi$ is a theorem. Then we need to prove that $\Gamma^{*} \Delta \vdash \varphi$ for every set $\Delta$ of wffs and whatever the meaning assigned to $*$, which is done by induction on the cardinality of $\Delta$.

Base case: $\Gamma * \Delta \vdash \varphi$ holds for $\Delta=\emptyset$.

$*$ means union: If $\Delta=\emptyset$, then $\Gamma \cup \Delta=\Gamma$. According to the first assumption, $\Gamma \vdash \varphi$. Then we obtain that $\Gamma \cup \Delta \vdash \varphi$.

$*$ means intersection: If $\Delta=\emptyset$, then $\Gamma \cap \Delta=\emptyset$. According to the second assumption, $\emptyset \vdash \varphi$ (by the definition of a theorem). Then we obtain that $\Gamma \cap \Delta \vdash \varphi$.

$*$ means relative difference: If $\Delta=\emptyset$, then $\Gamma-\Delta=\Gamma$. According to the first assumption, $\Gamma \vdash \varphi$. Then we obtain that $\Gamma-\Delta \vdash \varphi$.

Inductive hypothesis: $\Gamma * \Delta \vdash \varphi$ holds for $\Delta=\Delta_{\mathrm{n}}$ and whatever the meaning assigned to $*(\mathrm{n}=$ cardinality of $\Delta$ ).

Inductive step: $\Gamma^{*} \Delta \vdash \varphi$ holds for $\Delta=\Delta_{\mathrm{n}+1}$.

If $\Delta_{n+1}=\Delta \cup\{\psi\}$ (where $\psi$ is a wff such that $\psi \notin \Delta$ ), then $\Delta$ is of cardinality $\mathrm{n}$, and so the inductive hypothesis holds for it, i.e., $\Gamma^{*} \Delta_{\mathrm{n}} \vdash \varphi$ whatever the meaning assigned to *.

* means union: We need to prove that $\Gamma \cup \Delta_{n+1} \vdash \varphi$. Since $\Delta_{n+1}=\Delta_{n} \cup\{\psi\}$, it is the same as having to prove that $\Gamma \cup\left(\Delta_{\mathrm{n}} \cup\{\psi\}\right) \vdash \varphi$. By the associativity of the union, $\Gamma \cup\left(\Delta_{\mathrm{n}} \cup\{\psi\}\right)=\left(\Gamma \cup \Delta_{\mathrm{n}}\right) \cup$ $\{\psi\}$. By the inductive hypothesis, $\Gamma * \Delta_{\mathrm{n}} \vdash \varphi$ whatever the meaning of *. It follows that $\Gamma \cup \Delta_{\mathrm{n}} \vdash \varphi$. By the monotonicity of the consequence, $\left(\Gamma \cup \Delta_{\mathrm{n}}\right) \cup\{\psi\} \vdash \varphi$. By the associativity of the union, we obtain that $\Gamma \cup\left(\Delta_{\mathrm{n}} \cup\{\psi\}\right) \vdash \varphi$, i.e., $\Gamma \cup \Delta_{\mathrm{n}+1} \vdash \varphi$.

* means intersection: we need to prove that $\Gamma \cap \Delta_{n+1} \vdash \varphi$. Since $\Delta_{n+1}=\Delta_{n} \cup\{\psi\}$, it is the same as having to prove that $\Gamma \cap\left(\Delta_{\mathrm{n}} \cup\{\psi\}\right) \vdash \varphi$. As intersection distributes over union, $\Gamma \cap\left(\Delta_{\mathrm{n}} \cup\{\psi\}\right)=\left(\Gamma \cap \Delta_{\mathrm{n}}\right)$ $\cup(\Gamma \cap\{\psi\})$. By the inductive hypothesis, $\Gamma^{*} \Delta_{\mathrm{n}} \vdash \varphi$ whatever the meaning of $*$. It follows that $\Gamma \cap \Delta_{\mathrm{n}} \vdash$ $\varphi$. By the monotonicity of the consequence, $\quad\left(\Gamma \cap \Delta_{\mathrm{n}}\right) \cup(\Gamma \cap\{\psi\}) \vdash \varphi$. As intersection distributes over union, $\Gamma \cap\left(\Delta_{\mathrm{n}} \cup\{\psi\}\right) \vdash \varphi$, i.e., $\Gamma \cap \Delta_{\mathrm{n}+1} \vdash \varphi$.

* means set difference: we need to prove that $\Gamma-\Delta_{n+1} \vdash \varphi$. Since $\Delta_{n+1}=\Delta_{n} \cup\{\psi\}$, it is the same as having to prove that $\Gamma-\left(\Delta_{\mathrm{n}} \cup\{\psi\}\right) \vdash \varphi$. By one of the identities concerning relative complements, $\Gamma-\left(\Delta_{\mathrm{n}}\right.$ $\cup\{\psi\})=\left(\Gamma-\Delta_{\mathrm{n}}\right) \cap(\Gamma-\{\psi\})$. By the inductive hypothesis, $\Gamma * \Delta_{\mathrm{n}} \vdash \varphi$ whatever the meaning of $*$. It follows that $\Gamma-\Delta_{\mathrm{n}} \vdash \varphi$. The above result concerning intersection allows us to assert that if a wff is derivable from a set of wffs and is a theorem, than it is derivable from the intersection of that set and any

\begin{tabular}{|c|c|l|l|l|l|}
\hline intuitio & $\begin{array}{c}\text { ISSN } \\
1983-4012\end{array}$ & Porto Alegre & Vol.9- $\mathrm{N}^{\mathrm{o}} .1$ & $\begin{array}{l}\text { Julho } \\
2016\end{array}$ & p.28-34 \\
\hline
\end{tabular}


other set of wffs. Thus, we can assert that $\left(\Gamma-\Delta_{\mathrm{n}}\right) \cap \Delta \vdash \varphi$ for every set $\Delta$ of wffs. In particular, $\left(\Gamma-\Delta_{\mathrm{n}}\right) \cap$ $(\Gamma-\{\psi\}) \vdash \varphi$, which is the same as $\Gamma-\left(\Delta_{\mathrm{n}} \cup\{\psi\}\right) \vdash \varphi$, i.e., $\Gamma-\Delta_{\mathrm{n}+1} \vdash \varphi$.

\section{Q.E.D.}

The next meta-theorem establishes a link between the derivability of $\varphi$ from a given set $\Gamma$ of wffs when $\varphi$ is not a theorem and the existence of both a set $\Delta$ of wffs and an interpretation of $*$ such that $\varphi$ is not derivable from $\Gamma^{*} \Delta$ :

Meta-theorem 2 if $\Gamma \vdash \varphi$ and $\varphi$ is not a theorem, then there is at least one set $\Delta$ of wffs and one assignment of meaning to $*$ such that $\Gamma * \Delta \nLeftarrow \varphi$.

Proof we assume that $\Gamma \vdash \varphi$ and that $\varphi$ is not a theorem. It follows from the latter assumption that $\emptyset \Vdash \varphi$. We then consider a set $\Delta$ of wff such that if $\Gamma$ is infinite and contain all the wffs of $L, \Delta=\emptyset$; otherwise, $\Delta=\varnothing$ or is such that if $\psi$ is a wff and $\psi \in \Delta$, then $\psi \notin \Gamma$. In any case, $\Gamma \cap \Delta=\emptyset$. We then obtain that there is at least one set $\Delta$ of wffs and one operation between $\Gamma$ and this set such that $\Gamma^{*} \Delta \Vdash \varphi$.

\section{Q.E.D.}

The latter proof amounts to showing that if $\Gamma \vdash \varphi$ and $\varphi$ is not a theorem, it does not hold that for every set $\Delta$ of wffs and for every possible meaning assignable to $*, \Gamma * \Delta \vdash \varphi$. We then conclude the following:

Meta-theorem 3 if $\Gamma * \Delta \vdash \varphi$ for every set $\Delta$ of wffs and whatever the meaning assigned to $*$, then $\Gamma \nvdash \varphi$ or $\varphi$ is a theorem.

Proof by contraposition on meta-theorem 2.

The consequent of this latter meta-theorem is a disjunction whose first member denies that $\varphi$ is derivable from $\Gamma$. In order to present a criterion for theoremicity that involves the use of '*', one needs to rule out the first disjunct of that consequent, keeping everything else unchanged within meta-theorem 3. The following lemma shows the incompatibility between the antecedent of the meta-theorem 3 and the first conjunct of its consequent:

Lemma 1 if $\Gamma * \Delta \vdash \varphi$ for every set $\Delta$ of wffs and whatever the meaning assigned to $*$, then $\Gamma \vdash$ $\varphi$.

Proof We assume that $\Gamma^{*} \Delta \vdash \varphi$ for every set $\Delta$ of wffs and whatever the meaning assigned to * and that $\Gamma \nvdash \varphi$. Since $\Gamma^{*} \Delta \vdash \varphi$ irrespectively of which wffs make up $\Delta$, it is the case, in particular, that $\Gamma$ $* \Delta \vdash \varphi$ for $\Delta=\Gamma$. Furthermore, as $\Gamma * \Gamma \vdash \varphi$ whatever the meaning assigned to $*$, we are entitled to assert that $\Gamma \cup \Gamma \vdash \varphi$. However, $\Gamma \cup \Gamma=\Gamma$, and so $\Gamma \vdash \varphi$, which contradicts the second assumption. Q.E.D.

The proof of lemma 1 rules out the first conjunct of the consequent of meta-theorem 3 as a possible consequence of its antecedent. It is a bridge connecting meta-theorem 3 to the following result, of which we exhibit two proofs:

\begin{tabular}{|c|c|l|l|l|l|}
\hline intuitio & $\begin{array}{c}\text { ISSN } \\
1983-4012\end{array}$ & Porto Alegre & Vol.9- $\mathrm{N}^{\mathrm{o}} .1$ & $\begin{array}{l}\text { Julho } \\
2016\end{array}$ & p.28-34 \\
\hline
\end{tabular}


Meta-theorem 4 if $\Gamma * \Delta \vdash \varphi$ for every set $\Delta$ of wffs and whatever the meaning assigned to $*$, then $\varphi$ is a theorem.

Proof 1 we begin by assuming that $\Gamma * \Delta \vdash \varphi$ for every set $\Delta$ of wffs and whatever the meaning assigned to *. From this assumption, according to meta-theorem 3, it follows that $\Gamma \nvdash \varphi$ or $\varphi$ is a theorem. Lemma 1 allows us to assert the negation of $\Gamma \nvdash \varphi$ as following from the same assumption. Applying disjunctive syllogism to both consequences taken together, we obtain that $\varphi$ is a theorem. Q.E.D.

Proof 2 (by reductio ad absurdum): we begin by assuming that $\Gamma^{*} \Delta \vdash \varphi$ for every set $\Delta$ of wffs and whatever the meaning assigned to $*$ and that $\varphi$ is not a theorem. Insofar as $\varphi$ is supposedly derivable from any set, it must be case that $\Gamma^{*} \Delta \vdash \varphi$ for $\Gamma^{*} \Delta=\emptyset$. From the second assumption, however, we get that $\varnothing \Vdash \varphi$. Thus, $\varphi$ is a theorem.

Meta-theorem 4 establishes a sufficient condition for theoremicity. However, a criterion for such property involving the symbol '* demands that this same sufficient condition be laid down as a necessary condition. The next result does exactly that:

Meta-theorem 5 if $\varphi$ is a theorem, then $\Gamma * \Delta \vdash \varphi$ for every set $\Delta$ of wffs and whatever the meaning assigned to *.

Proof we assume that $\varphi$ is a theorem. It follows that $\varphi$ is derivable from any set of wffs whatsoever. In particular, $\Gamma * \Delta$ is a set of wff, as $\Gamma \cup \Delta, \Gamma \cap \Delta$ and $\Gamma-\Delta$ are all sets of wff, irrespectively of what formulae make up $\Delta$. We then readily obtain that $\Gamma^{*} \Delta \vdash \varphi$, whatever the meaning assigned to * and irrespectively of which wtffs make up $\Delta$.

Finally, we have the means to present a new criterion for theoremicity. It reads as follows:

Meta-theorem 6 (criterion for theoremicity) $\varphi$ is a theorem if and only if $\Gamma^{*} \Delta \vdash \varphi$ for every set $\Delta$ of wffs and whatever the meaning assigned to *.

Proof immediately from the conjunction of meta-theorems 4 and 5.

\section{Conclusion}

With the latter result, we accomplish what we had previously put forth as an aim, i.e., to show how the notions of a set of formulae, deducibility and operation over sets can be articulated into metatheorems regarding the property of theoremicity. Clearly, the piecemeal approach in the first proof presented above is only possible because the number of operations over sets is always finite. While quantification over sets of wffs in those results points towards an infinity of such objects - as the use of the metavariable ' $\varphi$ ' stands for an infinite number of wffs -, the operational variable '*' stands for a finite number of operations over sets. Nevertheless, even if we can do without operational variables in the presentation of a logical system, they happen to be useful for stating some definitions and meta-results.

\begin{tabular}{|c|c|l|l|l|l|}
\hline intuitio & $\begin{array}{c}\text { ISSN } \\
1983-4012\end{array}$ & Porto Alegre & Vol.9- $\mathrm{N}^{\mathrm{o}} .1$ & $\begin{array}{l}\text { Julho } \\
2016\end{array}$ & p.28-34 \\
\hline
\end{tabular}




\section{Bibliography}

CORCORAN, J. "Schemata: the Concept of Schema in the History of Logic". Bulletin of Symbolic Logic, Cambridge, vol.12, no.3, 219-40, 2006.

http://dx.doi.org/10.2178/bsl/1146620060

LUKASIEWICZ, J. Aristotle's Syllogistic from the Standpoint of Modern Formal Logic. 1.ed. Oxford: Clarendon Press, 1963, pp. 7.

. "On the History of the Logic of Propositions". In: MCCALL, S.; AJDUKIEWICZ (Ed.), Polish

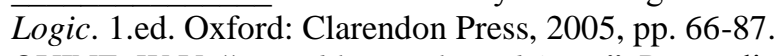

QUINE, W.V. "Variables Explained Away". Proceedings of the American Philosophical Society, Philadelphia, vol.104, no.3, 343-347, 1960.

2016-01-07

Data de Submissão: 07/01/2016

Aprovado para publicaçõ em: 21/06/2016

\begin{tabular}{|c|c|c|c|c|c|}
\hline intuitio & $\begin{array}{c}\text { ISSN } \\
1983-4012\end{array}$ & Porto Alegre & Vol.9- $\mathrm{N}^{\mathrm{o}} .1$ & $\begin{array}{l}\text { Julho } \\
2016\end{array}$ & p.28-34 \\
\hline
\end{tabular}

